\title{
Belarus' experience in post-Chernobyl communication with the local population, and some lessons learnt from involvement in the NERIS-TP project
}

\author{
V. Averin ${ }^{1,2}$ \\ 1 Research Institute of Radiology, Fedyuninsky Str. 16, 246000 Gomel, Belarus. \\ 2 Biology Department, Gomel State University n.a. Francysk Skaryna 102, Sovietskaya Str., 246000 Gomel, Belarus.
}

\begin{abstract}
This article presents the experience of post-Chernobyl management in Belarus associated with information interaction with the residents of the affected areas. It shows the evolution of the communication system throughout the whole period after the Chernobyl disaster, from communicating mostly with decision-making authorities in the first post-Chernobyl years to gradually shifting the major focus onto the public with the objective of promoting proactive attitudes towards restoration and development of the affected areas and improving the radiological culture of the affected residents. It also gives some important conclusions on the RIR's participation in the NERIS-TP project as a subcontractor to the Norwegian Radiation Protection Authority (NRPA). Despite the long-term experience of Belarus in post-accident management and the important results achieved by implementing various measures in the post-accident recovery period, there is presently a great necessity to pay due attention to the emergency preparedness for a potential new accident, in particular in view of the construction of the first NPP in Belarus.
\end{abstract}

Keywords: Belarus / Chernobyl disaster / communication / stakeholder involvement / information work

\section{Information work in the early years after the Chernobyl accident}

The post-accident national-local communication in Belarus has been a challenging process, gradually evolving after the Chernobyl disaster into a sustainable system of continuous and direct interaction between the national authorities and the residents of the affected areas.

During the first years of response, the top-priority tasks for the government's attention were related to the urgent measures such as evacuation, decontamination, radiation control and countermeasures, and it did not include much information sharing with the population, except for the respective officials' and specialists' presence.

Back in 1986, right after the Chernobyl accident, the USSR government gave directions to distribute among the affected public and specialists the recommendations on the rules of behaviour and economic activities in the area of radioactive contamination. By the end of 1986, a special information outreach plan of actions was developed for extension of radiological knowledge, primarily in the farm sector, which was to be implemented during the following 4 years. The document was called "The plan of activities on propaganda of knowledge in the field of agricultural radiology". It was focused mostly on communication with the agricultural specialists and local au- thorities, but it also included explanatory and educational activities involving the residents of the affected areas. The plan included lectures and meetings of visiting scientists with the public, specialists and officials in contaminated areas, radio and television broadcasts, popular science editions, and film production. Posters and memos were produced and distributed, and other efforts were made to promote radiological knowledge throughout the country.

However, despite all the efforts, the process of building trust with the population was neither easy nor fast. Regardless of the fact that the government and scientists were undertaking all the necessary actions to provide public health protection, there was a major lack in maintaining close communication with the residents. The people did not feel safe and had little confidence in both the actions being undertaken and their effectiveness. They could neither perceive nor adequately accept the large amount of unfamiliar information, and at the same time had a fear of food quality and health effects caused by radiation.

\section{Evolvement of the information work}

The way people perceived the radiation-related information has not been the same all the time. In fact, it changed over 
three different periods after the Chernobyl disaster. At first, the greatest public concerns were those related to the negative health effects and threats, especially to children's lives. After some time, the residents began to be troubled mostly with issues of local food quality and radiation doses. Finally came the stage of demand for advanced radiological education, sustainable enough to ensure sound health protection in the affected areas.

It was not until the beginning of the 21 st century that the government had fully recognised the vital importance of continuous public information sharing and started to finance and implement the new area of activities in the framework of the State Chernobyl Programmes. The main goal of this Information Work Programme was to provide in-depth education for the residents of the affected areas in order to change their behavioural pattern so that they could safely live and work in the context of radioactive contamination. It included social and psychological support, production of detailed maps, development and distribution of educational and methodological materials, training courses, field trips of experts, etc.

\section{Results}

At the present time, interaction with the population is carried out by different establishments at all levels. Not only the local authorities are involved, but also the top-level bodies (the Chernobyl Department and the Emergency Ministry), scientific institutions (including the Research Institute of Radiology), NGOs, radiation control organisations and others. Special training courses for healthcare and education professionals are held in the affected areas in order to teach the medical staff and teachers how to organise awareness-raising activities for different groups of the population and what information should be given. As for the residents of the affected areas, their radioecological skills are improved by different means, including public lectures held by experts, dissemination of radiation-related printed materials, meetings and professional consultations, etc.

The experience of such activities in Belarus has shown that among all the ways of improving the residents' knowledge on radiation safety in the affected areas, the most effective is to do it through children and youth. This is how the concept of the Centres for Practical Radiological Culture appeared. Created in rural schools in the affected districts, they now represent an essential element of Communication and Radiation Control systems. Unlike the existing radiation control centres, these new Centres not only perform measurements of radionuclide concentrations in food, but also carry out educational work with children and ensure dissemination of knowledge by involving their families and friends in this process. Based on food and whole-body measurement results, the Centres provide individual consultations, which imply informing critical citizens on the potential reasons for excess levels and the possible methods of their reduction.

Effective operation of Radiological Centres is achieved through close interaction with all relevant stakeholders, including schools, medical institutions, scientific organisations, mass media and local governmental bodies. Actions include educational lectures or more creative events; for instance, special films, lectures, stage plays, workshops, sports events, or other activities where local residents can be involved. The most significant result achieved due to the active informative and practical roles of the Centres is, of course, reduction of doses among the residents in the affected areas. Another positive effect of this work is the improved credibility in the fact that living in the affected territories is not only possible, but also safe. This view is shared by citizens across the country.

The successful communication and information work with the population in Belarus was not a simple task and it was not fully implemented until 2003, when the Information Concept on Chernobyl-related problems was adopted. Based on this concept, the system of interaction between different authorities and institutions was worked out with the objective of promoting proactive attitudes towards restoration and development of the affected areas, improving radiological culture and promoting overall positive attitudes of the citizens of the country to the affected areas. Starting from communicating mostly with decision-making authorities in the first post-Chernobyl years, the current information system was developed with a major focus on the residents of the affected areas, with the children as a target group.

\section{Relevance of the NERIS-TP project}

Being a part of the NERIS-TP project made us recognise something of no less importance: together with the success that has been achieved by implementing various measures in the post-accident recovery period in Belarus, one can admit the lack of due attention paid to the emergency preparedness for a potential new accident, particularly pertinent now with the construction of the first NPP in Belarus.

The present post-accident situation in Belarus has a completely different nature than it used to have in previous years. After 29 years, Belarus is gradually moving away from the post-accident recovery towards economic development of the areas, which is an official national policy established by the President of Belarus. Therefore, this is currently the last stage of the post-Chernobyl management, as we know it. Nevertheless, the actual situation is that despite the long-term experience in post-accident response and recovery, Belarus may need to go back to basics, realising the importance of wellestablished emergency preparedness systems for a potential new accident.

As a subcontractor to the NRPA, the Research Institute of Radiology has been carrying out a set of project activities within NERIS-TP with the overall objective of improving the cooperation system between national and local authorities and other stakeholders for the long-term post-accident radiation protection of the local population of the Bragin district. The choice of this particular location was made for a good reason: Bragin is a district area in the Gomel region located within $45 \mathrm{~km}$ of the Chernobyl NPP, i.e. the area which has directly experienced the consequences of a radiation accident and the burden of radioactive contamination.

While working in Bragin, we could see that, as time goes by, people's concerns about radiological issues become less and less vivid until they almost completely fade away in the 
face of prevailing economic-related concerns. This is particularly prominent in rural areas. Hence, the RIR was curious to consider not only the post-accident interaction towards radiation protection of the Bragin population, but also the state of nuclear emergency preparedness among residents and local authorities. During the technical visit of the Slovak delegates in Belarus in June 2013, a workshop was held in Bragin with the objective of studying both the recovery situation and the state of the emergency response in the Bragin district and comparing it with the system implemented in Slovakia. The Bragin participants were represented by officials from the regional and local structural units of the Ministry for Emergency Situations, local authorities and other stakeholders. The Bragin Workshop identified a set of weak places in the system of nuclear emergency preparedness at the local level. In comparison with the preparedness and response system presented by the Slovak specialists, and despite the past response experience, the current preparedness system has a number of gaps and uncertainties, including lack of due regard to the regular practical testing of preparedness abilities through training and exercises. Several issues have been recognised that need to be solved, thanks to the RIR's involvement in the NERIS-TP project and cooperative exchange visits.

\section{Conclusions}

The Bragin Workshop showed that even in the affected area it is vital to not only consider the current contamination (radiation safety), but also the state of emergency preparedness.
There is no reason to involve the whole population in preparedness and response; instead, special target groups must be identified (apart from the designated emergency units and teams) who potentially and voluntarily could be involved in the response, e.g. security guards, drivers, teachers and medical staff, who live in the vicinity of a NPP or other facilities of potential threat. These may also be the students of higher educational establishments who could/would potentially be involved in the emergency response actions in future. It is necessary to identify such individuals in advance, forming them into corresponding groups, and provide them with education and training. Involvement of these groups of volunteers should be based on the respective legislation established specifically to manage their participation in the emergency response and recovery processes securing radiation protection.

According to the Belarus experience, involvement of local stakeholders in the processes of post-accident management and emergency preparedness and response is very valuable, especially those who live in the vicinity of hazardous installations. The involvement should be initiated and motivated by the national and regional authorities, but also include scientists, NGOs and the public. Such initiatives are most effective when they are part of global initiatives, and international programmes or projects, like NERIS-TP. The assistance of national and international experts and researchers in projects implemented on the local scale has proven very useful.

Acknowledgements. This article was prepared and translated by Aliona Mikhailova, Director's Assistant/Interpreter of the Research Institute of Radiology.

Cite this article as: V. Averin. Belarus' experience in post-Chernobyl communication with the local population, and some lessons learnt from involvement in the NERIS-TP project. Radioprotection 51(HS1), S43-S45 (2016). 